\title{
Aglomeraciones productivas, territorio y abordajes teóricos para los estudios rurales*
}

\author{
Productive agglomerations, territory and theoretical \\ approaches for rural studies
}

\author{
Carlos Ayala-Durán ${ }^{1}$ \\ Investigador Postdoctoral, Pontifícia Universidade Católica do Rio Grande do Sul, Porto Alegre, Brasil \\ carlos.ayala@ufrgs.br \\ http://orcid.org/0000-0003-4049-671X
}

\author{
Augusto Mussi-Alvim² \\ Profesor Titular, Pontifícia Universidade Católica do Rio Grande do Sul, Porto Alegre, Brasil \\ augusto.alvim@pucrs.br \\ https://orcid.org/0000-0003-0130-6880
}

Paulo Dabdab-Waquil ${ }^{3}$

Profesor titular, Universidade Federal do Rio Grande do Sul, Porto Alegre, Brasil. waquil@ufrgs.br

http://orcid.org/0000-0002-9430-7040

Recibido: $16-11-18$

Aprobado: $27-08-19$

\footnotetext{
* El primer autor agradece el apoyo de CAPES/Brasil mediante el programa de beca postdoctoral PNPD.

1 Doctor en Desarrollo Rural.

2 Doctor en Economía.

3 Doctor en Economía Agrícola.
} 


\section{Resumen}

Ante la variedad de lentes teóricos para el estudio de aglomeraciones productivas, el presente trabajo tiene como objetivo central analizar y hacer una diferenciación de cinco marcos teóricos ampliamente utilizados: distritos industriales, clústeres, sistemas productivos locales, arreglos productivos locales y sistemas agroalimentarios localizados. Para ello, se emplea fundamentalmente como metodología la revisión de literatura teórica pertinente, utilizando cinco criterios de valoración: rigor teórico/metodológico, utilización en campo, forma de abordar el territorio, utilización explícita en temas agrícolas/agroindustriales y tamaño de las unidades de análisis. La reflexión realizada apunta a que el distrito industrial muestra gran fortaleza en términos de rigor teórico, a diferencia de enfoques como clúster o arreglos productivos locales. Similarmente, los distritos industriales, junto a los sistemas agroalimentarios localizados, resaltan la importancia del territorio en sus abordajes. Este último enfoque se muestra especialmente útil para el estudio de temas agrícolas y agroindustriales.

Palabras clave: concentración económica; economía rural; teoría económica; economía regional. Clasificación JEL: B40, R100, R120.

\section{Abstract}

Given the variety of theoretical lenses for the studies of productive agglomerations, the following paper has as a central objective to analyze and differentiate five widely used theoretical frameworks, namely: industrial districts, clusters, local productive systems, local productive arrangements and localized agri-food systems. For this purpose, the revision of pertinent theoretical literature is fundamentally used as a methodology, using five assessment criteria: theoretical / methodological rigor, use in the field, way of approaching the territory, explicit use in agricultural / agro-industrial issues and size of the analysis units. The reflection achieved indicates that industrial district shows great strength in terms of theoretical rigor, unlike approaches such as cluster or local productive arrangements. Similarly, industrial districts, together with localized agri-food systems, highlight the importance of the territory in their approaches. This last approach is especially useful for the study of agricultural and agroindustrial issues.

Keywords: Economic Concentration; Rural Economics; Economic Theory; Regional Economics.

¿Cómo citar este artículo? / How to quote this article?

Ayala-Durán, C., Mussi-Alvim, A. y Dabdab-Waquil, P. (2020). Aglomeraciones productivas, territorio y abordajes teóricos para los estudios rurales. Sociedad y economía, (39), 34-56. https://doi.org/10.25100/sye.voi39.7381 


\section{Introducción}

Históricamente, el territorio ha sido un instrumento analítico fértil en las ciencias sociales, abordado desde una variedad perspectivas científicas. Dentro de las disciplinas que históricamente han prestado atención al territorio destaca la geografía. Al interior de esta ciencia en particular, pueden identificarse diferentes escuelas de pensamiento que abordan y operacionalizan al territorio de múltiples formas. Existen notables diferencias entre las escuelas determinista, posibilista, geografía regional, nueva geografía, geografía crítica o geografía humana; tal como lo resumen Wives, Ayala, Senna y Kühn (2017). Pese a la preeminencia de la geografía en los estudios territoriales, existen también otras ciencias que se han preocupado por las dimensiones espaciales en sus propios campos de estudio. De tal suerte, las ciencias económicas han abordado de cierta forma la dimensión espacial de las relaciones económicas al menos desde el siglo XIX. En tal sentido, autores clásicos como Alfred Marshall ya abordaban el tema de la localización de las empresas en lugares específicos en su libro Principles of Economics, escrito a finales del siglo XIX. En sentido similar, Gottman (1975) ya resaltaba que desde la revolución industrial se evidenciaban importantes modificaciones en las relaciones entre las diversas secciones del espacio geográfico, al fomentarse la especialización de las diversas regiones en la producción o en el consumo de bienes determinados.

Tal interés por las relaciones espaciales y la economía se manifiesta de igual forma durante el siglo XX, ya que alrededor de los años cincuenta tuvo su incursión la ciencia regional o economía regional, de la mano de autores como Walter Isard o August Lösch. Al respecto, Lösch (1954), mediante su manual de economía Economics of Location, tomaba en cuenta la localización de actividades económicas en general, e incluso abordaba la localización de actividades agrícolas. Por su parte, Israd en su manual Location and Space-Economy, aborda por qué existirían aglomeraciones de firma, dando particular importancia a los costos de transporte (Isard, 1956).
Adicionalmente, y de forma más reciente, la dimensión espacial de las relaciones económicas pasó a ser de interés para otras disciplinas científicas menos ortodoxas dentro de las ciencias económicas, como la economía ecológica o la agroecología. Por ejemplo, dentro de la economía ecológica, el manual elaborado por Costanza, Cumberland, Daly, Goodland y Norgaard (1997) expresa la importancia de trabajar con líneas de insumos locales y la necesidad de que exista un control relativo a los medios de vida ${ }^{4}$ de las comunidades. Por su parte, entre los principios de la agroecología destaca la importancia de los conocimientos, materiales y experiencias locales (Gliessman, 2002; Gliessman y Rosemeyer, 2010).

De acuerdo con esta constante preocupación de las ciencias económicas por el abordaje espacial, la de vertientes territoriales sería una concepción útil para el análisis de la realidad, pues las acciones de los actores sociales, políticos e institucionales no serían vistas de forma estática, facilitando así una visión multi escalar, de lo global a lo local (Specht, 2009). En ese sentido, considerando una economía cada vez más globalizada y mostrando una interdependencia entre agentes económicos localizados más allá de las fronteras nacionales, la organización económica a nivel internacional experimenta cambios. Estas transformaciones, por su parte, tendrán consecuencias en sectores como la agricultura y la industria. Como lo expresan Racine, Raffestin y Ruffy (1983): "el aparato de producción reproduciéndose a una escala mundial, transnacional, provoca una tendencia a desarrollar regiones especializadas, mono actividades a nivel regional" (p. 133, traducción propia).

Ante este interés renovado de las ciencias económicas en considerar las dimensiones espaciales, es posible identificar una variedad de enfoques teóricos que abordan las aglomeraciones productivas en espacios determinados. Entre ellas, se pueden mencionar los distritos industriales, clústeres, arreglos productivos locales, sistemas productivos locales o los sistemas

\footnotetext{
4 De la palabra en inglés livelihood.
}

sociedad y economía • e-ISSN: 2389-9050 • No. 39, 2020 • pp. 34-56 
agroalimentarios localizados. De tal forma, al existir un número considerable de enfoques teóricos, se hace necesario tener claridad sobre cada uno de ellos, permitiendo utilizar el marco teórico más apropiado en virtud del problema de investigación específico a ser tratado. Esto reviste especial importancia ya que las teorías son construcciones abstractas que permiten interpretar la realidad y, como tal, inducen a abordar los problemas de investigación de formas diferentes.

De esa forma, teniendo como contexto la importancia del estudio de las dimensiones espaciales (particularmente de la territorial) y la necesidad de contar con marcos analíticos sólidos para los estudios del mundo rural, el presente trabajo tiene por objetivo analizar las diferencias entre cinco enfoques teóricos que abordan las aglomeraciones productivas, a saber: distritos industriales, clústeres, arreglos productivos locales, sistemas productivos locales y los sistemas agroalimentarios localizados. Para tal fin, estos diversos enfoques teóricos son analizados en función de cinco aspectos: rigor teórico/metodológico, posibilidad para intervención en campo, abordaje territorial, abordaje explícito de temas agrarios/agroindustriales y tamaño de las unidades de análisis empleado. Adicionalmente, el presente trabajo resalta algunas implicaciones prácticas en la utilización de los mencionados enfoques en investigación. Como el presente trabajo es de naturaleza abstracta y teórica, se parte a continuación de una breve caracterización y definición de los mencionados enfoques que abordan aglomeraciones productivas. Posteriormente, se resaltan las diferencias entre los mismos. Y, por último, se discuten algunas implicaciones de tales diferencias en las consideraciones finales.

\section{Definición de los enfoques}

Inicialmente, dos de los enfoques más conocidos para describir aglomeraciones productivas en espacios restringidos son los clústeres y los distritos industriales. Esto obedece a que los distritos industriales fueron una construcción teórica desarrollada durante las décadas de 1970 y 1980, mientras que los clústeres se fraguaron durante los años 1990. Tales enfoques tienen algunas similitudes, no obstante, descansan sobre una serie de diferencias importantes, como se verá a continuación.

\subsection{Clúster y Distritos Industriales}

En primer lugar, los clústeres son un enfoque de origen estadounidense, formulados por Michael Porter, que hace referencia a aglomeraciones productivas. Este enfoque es desarrollado en diversos escritos, particularmente en el libro The Competitive Advantage of Nations, y posteriormente condensado en un artículo de la escuela de negocios de Harvard homónimo del mencionado libro (Porter, 1990). En el artículo, Porter realiza un amplio estudio en diez países que lideran el comercio internacional, con el objetivo de identificar los factores que influyen en la competitividad de las industrias en tales países. Según el autor, los factores son: componentes de oferta, condiciones de deman$\mathrm{da}$, industrias relacionadas, y la estrategia empresarial estructura y rivalidad (Porter, 1990). Elementos que serían esquematizados mediante el famoso diamante de Porter.

En virtud de esta construcción en torno a la competitividad, Porter (1990) señala que, usualmente, los países cuentan con más de una industria competitiva a nivel internacional, lo que crea el ambiente propicio para la formación de agrupaciones de empresas, es decir, para la formación de clústeres. Dado el nivel de análisis que incluía varios países, los clústeres fueron una construcción teórica sujeta al interés de diversos órganos gubernamentales a nivel internacional (Martin y Sunley, 2003).

Por su parte, autores como Sforzi (2015) o Malmberg y Power (2005) ven que originalmente Porter visualiza a los clústeres sólo como industrias funcionalmente relacionadas entre sí por vínculos verticales (comprador, proveedor) u horizontales (tecnología y clientes comunes, canales de distribución, etc.), pero sin mayores vínculos territoriales. De esa forma, tales industrias mostrarían una tendencia a 
concentrarse geográficamente, siendo que esta proximidad amplificaría los mecanismos de innovación y dinamismo de los clústeres (Sforzi, 2015, Malmberg y Power, 2005). Con el paso de los años, la relación funcional de las industrias formando clústeres cambiará ya que, posteriormente, la misma definición de clúster de Porter (1998a) abordará de forma explícita la concentración geográfica, definiendo a estos conglomerados como:

\begin{abstract}
Concentraciones geográficas de empresas interconectadas, proveedores especializados, proveedores de servicios, firmas industriales relacionadas e instituciones asociadas (por ejemplo, universidades, agencias de estandarización y asociaciones comerciales) en campos particulares, que compiten pero también cooperan (p. 3, traducción propia).
\end{abstract}

Con ello, esta definición ya integrará de forma clara la cuestión espacial de las actividades económicas. En trabajos posteriores, tal definición de clúster se verá nutrida por el mismo autor al adicionar que las mencionadas aglomeraciones estarían interconectadas por complementariedades (Porter, 2000). Siendo que, al principio, los clústeres no abordaban detenidamente el lugar donde ocurrían las actividades económicas, y que ese espacio era sólo un sustrato material donde se daba el aumento de la competitividad empresarial, existen autores como Sforzi (2015) aseverando que este viraje geográfico de Porter obedece a la influencia en la década de los años 1990 del concepto de distrito industrial (DI). Con ello, el foco de los clústeres desde la visión de Porter no era originalmente la cuestión espacial de las actividades económicas, sino la competitividad de las empresas/países. De tal forma, el lugar donde suceden actividades económicas se mostraría importante debido a que el lugar afecta la ventaja competitiva (Porter, 2000). Siendo así, el abordaje de los clústeres no centra usual y explícitamente a las comunidades locales, normas culturales o valores asociados a tales lugares; temas que muestran su influencia en el espíritu emprendedor de la aglomeración (Sforzi, 2015). Pese a la existencia de esta aparente miopía, el trabajo sobre clústeres realizado por
Altenburg y Meyer-Stamer (1999) sí explora las particularidades de las comunidades donde se localiza la aglomeración productiva, así como las relaciones con el territorio donde acontece la aglomeración.

Como se ha mencionado, autores como Sforzi (2015) consideran que los distritos industriales (DI) tuvieron un papel destacado para el viraje de los clústeres sobre el espacio donde acontecía la aglomeración. Estos distritos industriales (DI) han sido una construcción teórica originalmente adjudicada al economista italiano Giacomo Becattini, quien trabajó temas de economía industrial en Italia desde la década de los años 1970. Inspirados en los distritos industriales marshalianos del siglo XIX, el re-surgimiento de este enfoque se daba en el contexto de los años setenta y ochenta donde, a pesar de que varias regiones de Europa experimentaban recesión e incluso estagnación económica, se evidenciaban de forma paralela algunos lugares del viejo continente que mostraban gran resilencia e incluso crecimiento económico (Pyke y Sengenberger, 1990). Originalmente, en su libro Principles of Economics, publicado en 1890, Marshall hacía referencia a industrias localizadas que habrían allanado el camino en temas como la gestión empresarial y la división del trabajo en los oficios mecánicos (Marshall, 1895). En aquel momento, Marshall veía que la localización de industrias en espacios determinados se daba principalmente en función de: a) condiciones físicas como el clima, condiciones del suelo, existencia de minas o acceso fácil por vías de comunicación; y b) de la existencia de una corte, al ser un público selecto que demandaba bienes de primera calidad (Marshall, 1895). En su libro, Marshall también abordaba ideas como el agrupamiento de artesanos cualificados, la imitación de nuevas ideas de negocios, oferta en el mercado del trabajo cualificado y las industrias de carácter suplementario.

De esta forma, al final de la década de 1970, Becattini (1979), citado en Brusco (1990), hace una interpretación y actualización de los distritos industriales marshallianos, realizando un trabajo de investigación que se considera uno de los puntos iniciales para la conformación de 
una teoría estructurada contemporánea sobre los distritos industriales. Con este escrito, la idea era que la unidad de análisis dejaría de ser la firma o empresa, pasando a ser una serie de empresas interconectadas en un área pequeña (Brusco, 1990) llamada distrito industrial. Con ello, en virtud del trabajo de Becattini (1979), citado en Brusco (1990), el foco de análisis pasaría a ser el distrito industrial definido como:

\begin{abstract}
Entidad socio territorial que se caracteriza por la activa presencia de una comunidad de personas y un número de empresas en un área natural o históricamente homogénea. En el distrito, a diferencia de otros ambientes como las ciudades manufactureras, la comunidad y las empresas tienden a fusionarse (Becattini, 1990, p. 38, traducción propia).
\end{abstract}

Es destacable que desde el inicio de la concepción de los distritos industriales, la misma está impregnada de una vertiente territorial de forma explícita. En ella, se abordan costumbres, formas de comportarse, valores, entre otros; que son claves para la reproducción del Distrito Industrial (Becattini, 1990). Con ello, para Becattini (1990):

\begin{abstract}
El rasgo más importante de la comunidad local es su sistema de valores y visiones relativamente homogéneas, lo que es una expresión de la ética de trabajo, de la familia, de la reciprocidad y del cambio. En alguna medida, todos los aspectos del trabajo están afectados por tales factores. El sistema de valores existente en el distrito se desarrolla más o menos rápidamente en el tiempo, en formas aún por explorar; constituye uno de los requisitos preliminares para el desarrollo del distrito, y es asimismo una de las condiciones esenciales para su reproducción (p. 39, traducción propia).
\end{abstract}

Bellandi y De Propris (2015) identifican tres generaciones de distritos industriales: a) los teorizados por Marshall, b) los teorizados por Becattini en un ambiente post fordista, y c) los distritos en la era de producción global. En estos últimos distritos industriales, se estarían incluso cuestionando aspectos descritos en las décadas de 1980 y 1990 alrededor de tales conglomerados, ya que se flexibiliza el tamaño de las empresas, abarcando la inclusión de grandes firmas (Sforzi y Mancini, 2012; Bellandi y De Propris, 2015).

El desarrollo de los distritos industriales fue un instrumento que permitió analizar la lógica del desarrollo industrial de la llamada tercera Italia desde los años ochenta. Esto posibilitó estudiar la industria italiana, con sus repercusiones principalmente en Europa, desde una visión que excedía el tradicional sesgo del sector industrial, usualmente marcado por una perspectiva político administrativa a nivel municipal o estadual (Sforzi, 2015). Originalmente, la importancia económica de los distritos industriales se vio evidenciada en diversos estudios, como los realizados en Italia por Capecchi (1990) y Sforzi (1990). Este último autor calculaba que existían 61 distritos industriales en toda Italia en la década de 1980; principalmente en la industria de la ropa y de la mueblería de madera (Sforzi, 1990). Según Sforzi (1990), para el año 1981, en media el $11,9 \%$ del empleo industrial -en sus sectores respectivos- provenía del generado en los distritos industriales.

Este tipo de investigación no hubiera sido posible sin una delimitación clara y una formalización de lo que sería la unidad territorial de análisis apropiada, es decir, los distritos industriales. Para tal fin, se elaboró una base cuantitativa/estadística que reforzase la construcción teórica de los distritos industriales. De esa forma, durante la década de los ochenta el foco de estudios se desplaza desde las unidades políticas (usualmente municipalidades, regiones, etc.) hacia las áreas de mercado local de trabajo ${ }^{5}$ (Sforzi, 1990; 2012; ISTAT, 2001). Mediante un sistema de ecuaciones, tales áreas se identificaban basándose en indicadores estadísticos de los recorridos diarios que las personas realizaban desde sus domicilios a sus lugares de trabajo, lo que implicaba muchas veces desplazamiento entre unidades político administrativas diferentes (Sforzi, 1990; 2012). Una vez identificadas, las

5 Originalmente del italiano Sistemi Locali del Lavoro, o en inglés Local Labour Market Areas (LLMAs). 
áreas de mercado local de trabajo eran analizadas para comprobar cuáles de ellas respondían a áreas de industrialización leve/temprana ${ }^{6}$, identificándose con ello los llamados sistemas locales de trabajo (Sforzi, 1990). Finalmente, los sistemas locales eran analizados para ver cuáles respondían a una especialización en manufactura, mismos que serían abordados como distritos industriales. Este refinamiento en la identificación y delimitación de los distritos industriales revestía gran importancia, ya que en palabras de Sforzi (2012):

El distrito era un concepto en búsqueda de evidencia empírica para ser reconocido como un instrumento de análisis efectivo para la interpretación del desarrollo económico italiano basado en las pequeñas empresas. Hasta ese momento, la importancia de las pequeñas empresas para el desarrollo económico se basaba en evidencia anecdótica. La evidencia empírica, respaldada por un enfoque estadístico fiable, mostró que los distritos industriales eran responsables por una gran parte de la economía italiana. Asimismo, mostró que las pequeñas empresas, cuando se abordaban con el modelo del distrito, podían ser tan competitivas como una empresa grande (pp. 14-15, traducción propia).

Pese a algunas limitaciones asociadas a esa metodología, como su rigidez o problemas para identificar distritos poli-especializados (Boix y Galleto, 2008; Boix y Trullén, 2011), su formalización, bajo el amparo del Instituto Nacional de Estadística italiano, permitió consolidar la metodología y proveer mecanismos claros para la identificación y el análisis de los distritos industriales.

Dado que tanto clústeres como distritos industriales abordan arreglos productivos, en ocasiones los dos enfoques son sujetos de confusión. En algunos casos, los investigadores se apropian de uno de estos referentes en particular sin mayor valoración de otras opciones similares. $\mathrm{Al}$ respecto, Kim (2015), citado en Belussi (2015), llama clúster al sistema de biotecnología de San Diego, si bien el autor describe sus características como si de un distrito industrial se tratara. Asimismo, la industria de Silicon Valley en Los

\footnotetext{
6 En inglés light industrialization.
}

Ángeles es teorizada como distrito industrial por Pyke y Sengenberger (1990), mientras que Porter (1998a; 1998b; 2000) los aborda como clústeres. En sentido similar, la industria de las cerámicas localizada cerca de Sassuolo en Italia es abordada como distrito industrial por Cappechi (1990) y por Pyke y Sengenberger (1990), mientras que para Porter (1990) y Hervas y Boix (2013) esta industria se encajaría en los clústeres. De tal forma, Belussi (2015) se pregunta -a forma de ejemplo- si la industria de la tecnología de Sillicon Valley es un clúster o un distrito industrial. La autora italiana concluye haciendo una cierta apología en la utilización indistinta de clúster o distrito industrial al afirmar:

\begin{abstract}
En conclusión, debemos admitir que vivimos en un mundo académico donde existe una amplia ambigüedad semántica. Lo que en el norte de Europa era llamado "clúster" (Maskel, 2001) o "learning region" (Asheim, 2006), es en realidad una teorización Marshaliana de un distrito industrial "maduro", mientras que en Italia, el término distrito industrial era usado para definir diferentes tipos de DI/C (Paniccia, 1998). (Belussi, 2015, p. 93, traducción propia).
\end{abstract}

Pese a la utilización análoga de tales enfoques, los mismos difieren sustancialmente en función de su robustez teórica. De esa forma, Martin y Sunley (2003) consideran que la definición de clúster es vaga en términos de la escala geográfica y de su dinámica socioeconómica, lo que hace posible que cualquier investigador pueda adaptar y moldear la idea de clúster de una manera que se ajuste a sus necesidades particulares. Con ello, los autores hacen hincapié en la dificultad de definir los límites tanto industriales como geográficos de los clústeres (Martin y Sunley, 2003). Por otra parte, autores como Malmberg y Power (2005) argumentan que existen problemas incluso a la hora de saber de forma certera qué es un clúster o a qué hace referencia el clustering de empresas; llegando a llamar a este enfoque como un dolor de cabeza. Parte de la confusión puede emanar del hecho de que clúster 7 per se es una palabra de origen inglés difícil de traducir, que podría ser interpretada

7 Según el diccionario de Cambridge, clúster es: "a group of similar things that are close together, sometimes surrounding something" (Cambridge Dictionary, 2018).

sociedad y economía • e-ISSN: 2389-9050 • No. 39, 2020 • pp. 34-56 
como conjunto, lo que implica en su origen una naturaleza agrupadora ${ }^{8}$. Con ello, la extrapolación del término para la agrupación de empresas en las condiciones expresadas por Michael Porter, se vuelve desde un inicio ambigua. En un sentido similar, Martin y Sunley (2003) consideran a este enfoque como difuso, al utilizar una construcción genérica, vaga, así como lo suficientemente indeterminada para encajarse según los intereses de investigadores en particular. El mismo Michael Porter, refiriéndose específicamente a la delimitación de los clústeres, reconoce que demarcar sus fronteras es -usualmente- una cuestión de perspectiva que requiere de un proceso creativo, haciendo necesario comprender los vínculos y complementariedades entre las industrias (Porter, 1998c citado en Huggins y Izushi, 2011). De tal suerte, Martin y Sunley (2003) ponen en duda la robustez teórica de los clústeres afirmando:

\begin{abstract}
En lugar de ser un modelo o teoría a ser comprobado y evaluado rigurosamente, la idea de clúster se ha aceptado fundamentalmente como una "forma de pensar" válida y significativa sobre la economía nacional, una plantilla o procedimiento con el cuál se descompone la economía en agrupaciones geográficas de distrito industrial, con el propósito de entender y promover la competitividad y la innovación (p. 9, traducción propia).
\end{abstract}

La discusión sobre clúster y distritos industriales se ha visto materializada en importantes producciones científicas. Sobre clústeres, por ejemplo, Altenburg y Meyer-Stamer (1999) elaboran un artículo particularmente robusto, al discutir de forma teórica los clústeres en América Latina, pero aportando paralelamente elementos empíricos en casos como la industria automotriz en Puebla (México), o las industrias electrónicas en Guadalajara (México) y Costa Rica. Para el caso de distritos industriales, los trabajos de Boix y Galletto (2008) y Boix y Trullén (2011) presentan aplicaciones empíricas sustanciales para las industrias españolas.

8 Para ver de forma rápida varias definiciones de clúster según diversos autores, consultar la esquematización de Martin y Sunley (2003, p. 12).
Una vez estudiados los distritos industriales y el clúster, se pasa a analizar tres enfoques utilizados ampliamente para los estudios en América Latina: SPL, APL y SIAL. Estos son relativamente más recientes y representan abstracciones que abordan también aglomeraciones productivas en torno a espacios específicos. Los mismos guardan cierta similitud, como se pretende ilustrar a continuación.

\subsection{Sistemas Productivos Locales (SPL), Arreglos Productivos Locales (APL) y Sistema Agroalimentario Localizado (SIAL)}

Centrándose en los SPL, Courlet (2001) señala que la tradición de los distritos industriales becantianos se desarrolló inicialmente en Italia, expandiéndose en una ola inicial hacia países industrializados como Alemania, Dinamarca, Japón o Francia. Posteriormente, este abordaje fue aplicado a países europeos de industrialización tardía, como Portugal o España, para finalmente calar en los llamados países en desarrollo (Courlet, 2001). Con ello, Courlet (2001; 2013) señala que esta ampliación, al utilizar los distritos industriales como medio para interpretar numerosas aglomeraciones productivas, trajo consigo que tal enfoque perdiera su rigor técnico; especialmente en lo referido a la homogeneidad y a las características socioculturales que fundamentan los distritos industriales. En un sentido similar, para Requier-Desjardins (1999), la evolución de los distritos industriales dio paso a mostrar una diversificación y heterogeneidad crecientes en las unidades involucradas, permitiendo el ingreso de grandes empresas, algunas de ellas inclusive ajenas a los propios distritos industriales9. Esta pérdida de rigor técnico justificaría la emergencia de los sistemas productivos locales (Courlet, 2001; 2013) definidos como:

9 Pese a esta observación del autor francés, como fue mencionado anteriormente, autores como Brusco (1990) ya abordaban en la década de los años noventa la posibilidad que las empresas dentro de los distritos industriales fueran grandes. De forma similar, más recientemente, autores como Sforzi y Mancini (2012) o Bellandi y De Propris (2015) abordan abiertamente empresas de gran tamaño en los distritos industriales. 
Conjunto caracterizado por la proximidad de las unidades productivas en el sentido amplio del término (empresas industriales, de servicios, centros de investigación y formación, interfaces, etc...) que mantienen entre sí relaciones más o menos intensas. La intensidad de los lazos entre las unidades de producción depende, antes que nada, de la forma de organización y del funcionamiento del sistema productivo (Courlet, 2001, p. 88; traducción propia).

Por su parte, Cassiolato y Szapiro (2002) definen los sistemas productivos locales (SPL) como aglomerados de agentes económicos, políticos y sociales; localizados en un mismo territorio, que presentan vínculos consistentes de articulación, interacción, cooperación y aprendizaje; volcados a la introducción de nuevos productos y procesos. Para Rendón y Forero (2014), los sistemas productivos locales pueden ser definidos como estructuras o modos de organización empresariales orientados a la producción y comercialización de un determinado bien o servicio. Gracias a un ejercicio académico mucho más riguroso, Madruga-Torres (2014) definirá los SPL, específicamente para el caso cubano como:

\footnotetext{
El espacio de interacción definido por las relaciones entre empresas con funciones específicas en cada fase del proceso de producción con presencia de especialización en las relaciones productivas, que se pueden manifestar mediante la generación de vínculos territoriales entre estas e instituciones, existiendo una interacción continua entre la actividad económica, cultural, social y política; presentando una estructura organizativa que dirige las funciones en el espacio definido, donde existe una complementación de funciones entre los diferentes agentes locales orientados a fortalecer la capacidad de conocer, aprender e innovar, convirtiéndolo en un núcleo fundamental de la dinámica de una economía local (Madruga-Torres, 2014, p. 7).
}

A pesar de que para Courlet (2001; 2013) los SPL serían una respuesta a la pérdida de rigurosidad de los distritos industriales, autores como Requier-Desjardins, Boucher y Cerdan (2003) reconocen la importancia de los distritos industriales en los SPL al afirmar:

El análisis teórico de la dinámica de los sistemas productivos locales está arraigado en el trabajo de Marshall, que resaltaba el papel de la proximidad geográfica como un factor de difusión de externalidades tecnológicas específicas (fuerza de trabajo, difusión de innovaciones, etc.). Aparece como una aplicación de la rama teórica sobre externalidades direccionada a las concentraciones geográficas de empresas pertenecientes a un mismo sector. Los Neo Marshallianos (Beccatini, 1979) abordan estas externalidades al resaltar la importancia de compartir valores comunes, hábitos y experiencia histórica; que conformarían una identidad común y la base social de emprendedores. Esto permitiría una mejora en la difusión de información y desarrollo de cooperación (p. 53, traducción propia).

Con ello, y dadas sus particularidades, los SPL parecerían más una adaptación "a la francesa" de los distritos industriales desarrollados en Italia; principalmente desde la década de los años ochenta. De forma similar, los SPL se han nutrido de la larga tradición de estudios sobre los distritos industriales, siendo que estos sistemas productivos locales serán abordados por académicos franceses más como una noción general y distendida que abordaría diversas formas de aglomeración productiva, reconociendo la existencia de otros enfoques como clúster o distritos industriales, por ejemplo (Requier-Desjardins, 2010).

Muy relacionados estarían los arreglos productivos locales (APL). Desde una perspectiva de política pública, Cardoso (2014) definirá a los APL de forma bastante similar a los SPL:

\footnotetext{
Un arreglo productivo local es una aglomeración de empresas localizadas en un mismo territorio, que presentan especialización productiva y mantienen vínculos de articulación, interacción, cooperación y aprendizaje entre sí y con otros actores locales, tales como: gobierno, asociaciones empresariales, instituciones de crédito, enseñanza e investigación (p. 7, traducción propia).
}

La literatura resalta que los arreglos productivos locales (APL) se refieren a aglomeraciones menos estructuradas $y$

sociedad y economía • e-ISSN: 2389-9050 • No. 39, 2020 • pp. 34-56 
condensadas que los sistemas productivos locales (SPL). De tal forma, según Cassiolato y Szapiro (2002), los arreglos productivos locales hacen referencia a aquellas aglomeraciones productivas cuyas interacciones entre los agentes locales no son lo suficientemente desarrolladas para llamarlas sistemas. En sentido similar, Herrera (2014) considera que la principal diferencia de los APL en relación con los SPL es la debilidad de los vínculos entre los actores locales. Adicionalmente, para Teixeira, Amaral-Filho, Mayorga y Mayorga (2006), los APL poseen una estructura menos desarrollada, teniendo como características predominantes: la informalidad y su nacimiento, en función de las demandas de regiones particulares. De esta forma, los arreglos productivos locales (APL) serían aglomeraciones de empresas anteriores y más básicas que los sistemas productivos locales; por lo tanto, los SPL serían una fase más evolucionada de los APL. No obstante, no es posible determinar indicadores claros que ayuden a discernir en qué momento los APL comienzan a desarrollarse de tal forma para que se tornen como SPL. Pese a que estudios como los de Lastres y Cassiolato (2005) consideran que los APL son aglomeraciones fragmentadas que carecen de una articulación significativa entre sus actores para ser llamados SPL, los autores no definen en qué momento podría considerarse que una articulación APL alcanzó el nivel propio de un SPL.

Junto con esta confusión sobre la utilización de los términos y la distinción del tipo de aglomerado, existe un problema epistemológico en relación a estos dos abordajes, particularmente en regiones subdesarrolladas como Latinoamérica. Específicamente, dada la estructura de las economías de esta región, con el nivel de innovación más limitado y aprendizajes más incipientes, surge la pregunta: ¿puede considerarse la existencia de aglomeraciones económicas lo suficientemente articuladas para que sean consideradas sistemas productivos locales? O, en su lugar, y dadas las condiciones imperantes, ¿es únicamente posible la creación de aglomerados productivos locales a nivel de arreglos? En ese sentido, los estudios de Herrera (2014) y Madruga-Torres (2014) abordan tal dicotomía para el caso específico de Cuba. Madruga-Torres (2014) elabora una definición de SPL para aquel país caribeño, tomando en consideración 53 definiciones de SPL, distrito industrial y clúster. No obstante, Herrera (2014) considera que dadas las condiciones de subdesarrollo de muchos países, donde existe un desarrollo insuficiente de las fuerzas productivas, se torna mucho más complejo poder consolidar redes productivas fuertes. De esta forma, la autora recalca: "Los APL constituyen un ajuste apropiado a las condiciones del subdesarrollo en tanto su conceptualización refleja realmente lo que acontece en condiciones de insuficiente desarrollo de las fuerzas productivas" (Herrera, 2014, p. 156). En tal sentido, lo que permanece en la base de la discusión es la posibilidad de alcanzar un nivel suficiente de innovación y desarrollo de las fuerzas productivas para poder considerar estas relaciones como sistemáticas.

Pese a que sea posible identificar problemas con la utilización y aplicación de estudios prácticos de SPL y APL, o que existan dificultades para algunos países en articular sistemas productivos locales, tales enfoques ya toman en consideración las relaciones espaciales de actividades económicas, y en algunos casos se apropian de elementos comunes de una visión territorial. Como destaca Madruga-Torres (2014), al referirse a los SPLs (pese a que esto sería válido también para los APLs), el territorio no es únicamente el soporte físico de los procesos productivos, ya que este se transforma en un componente activo del desarrollo.

Finalmente, los Sistemas Agroalimentarios Localizados emergen como una forma de análisis de aglomeraciones productivas en respuesta a los problemas presentados por las agroindustrias rurales en América Latina (Boucher y Riveros, 1995). Muchnik (2006) señala que la década de los noventa fue testigo de un aumento en las crisis de las sociedades rurales, junto al empeoramiento de los problemas ambientales y alimentarios. En sentido similar, Boucher y Pomeón (2010) destacan que las agro industrias rurales enfrentaban nuevos desafíos: cambios en los arreglos de distribución, aumento en la competencia de productos industriales, nuevas exigencias por parte de los consumidores y la 
permanencia o incluso el aumento de la pobre$\mathrm{za}$ en las zonas rurales. Es precisamente en el contexto de cambios en el mundo rural, en la agricultura, en la producción agroalimentaria y en el consumo de alimentos que surgen los sistemas agroalimentarios localizados (Muchnik, 2006). Originalmente, los sistemas agroalimentarios localizados fueron definidos como:

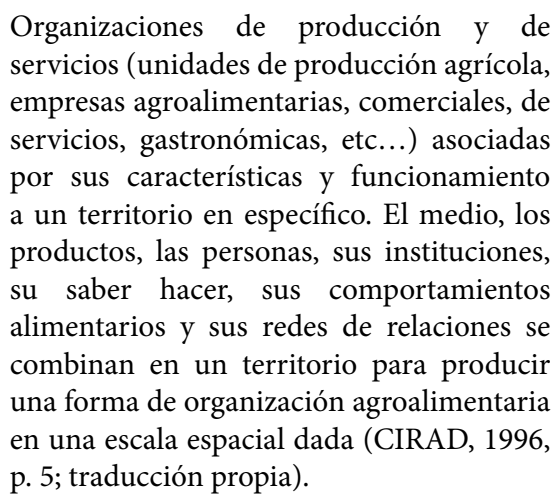

El enfoque SIAL era inicialmente estructurado en torno a tres ejes temáticos: a) productos locales adaptados a consumidores urbanos, b) el conocimiento, saber hacer y otras técnicas perfeccionadas socialmente, y c) los recursos de las unidades de producción locales (CIRAD, 1996). Pese a ello, Muchnik (2006) teorizó posteriormente los SIALs en torno a cuatro dimensiones: histórica, institucional, técnica y alimenticia.

La dimensión histórica permitiría, según Muchnik (2006), apreciar el proceso de formación de las experiencias estudiadas. Para Ambrosini, Filippi y Miguel (2008), el sentimiento de pertenecer y la valorización de identidades formadas por una historia común podrían encajarse dentro de la dimensión histórica. La dimensión institucional tendría como foco las relaciones entre los actores sociales y sus estrategias individuales y/o colectivas (Muchnik, 2006). Por su parte, la dimensión técnica estaría enfocada en la observación, descripción y análisis de los saberes y técnicas utilizadas (Muchnik, 2006). En tal dimensión estaría incluído el know-how o saber hacer para el cultivo o transformación de los productos agroalimentarios (Ambrosini, Filippi y Miguel, 2008; Specht, 2009). Finalmente, la dimensión alimenticia estaría preocupada por las relaciones (sociales, culturales, económicas) entre el producto y el consumidor (Muchnik, 2006). Los productos de un SIAL se diferencian por características intrínsecas propias de un ambiente determinado (Specht, 2009), lo que haría que diferentes alimentos, en diferentes contextos, tengan diferentes significados.

Los sistemas agroalimentarios localizados son concebidos como sistemas productivos locales (SPL) exclusivos del sector agroalimentario (Requier-Desjardins, 2010; Salcido, 2017). Recientemente, Salcido va más allá al explicar la particularidad del SIAL:

\begin{abstract}
El Sial es una forma de sistema productivo local. Pero su particularidad reside en su identificación con sistemas territoriales basados en los bienes destinados al consumo alimenticio. Es decir, productos que se metabolizan en el cuerpo humano. Sin embargo, el hecho distintivo más importante es que los Sial estudian los alimentos como hecho social y cultural. La alimentación es un hecho social total, mediante el cual se puede analizar y comprender la forma en la que los seres humanos se relacionan e intercambian bienes, trabajan y construyen símbolos de identidad cuya característica fundamental es un enraizamiento profundo (embeddedness) de la economía en la sociedad y el territorio (Salcido, 2017, p. 24).
\end{abstract}

En virtud de que el SIAL es considerado como una vertiente agroalimentaria de los SPL, las discusiones sobre el territorio tendrán también un papelcentral en este enfoque. Envirtud de ello, Muchnik y Sautier (1998) conciben al territorio -en el contexto del SIAL- como el espacio construido histórica y socialmente, donde las actividades económicas están condicionadas por las relaciones de proximidad. De forma paralela, Boucher (2006) resalta que existen una proximidad geográfica y una proximidad organizacional al interior del territorio. La primera de ellas estaría inducida por un espacio determinado que favorecería las externalidades pasivas (disponibilidad de mano de obra y dinámicas de innovación) (Boucher, 2006). Por otra parte, la proximidad organizacional pondría en evidencia el comportamiento 
de actores económicos al compartir reglas y representaciones comunes (Boucher, 2006). La comprensión de la proximidad -en estos términos- justificaría parcialmente el hecho de que los límites espaciales de los SIAL pueden ser flexibles, grandes e incluso abarcar regiones en ocasiones discontinuas; como micro cuencas e incluso archipiélagos ${ }^{10}$ (Requier-Desjardins, 2010).

Los SIAL, siendo una herramienta emanada de dos instituciones que trabajan en temas de agricultura y desarrollo (CIRAD, IICA), tienen arraigado desde su origen ser una herramienta para poder intervenir comunidades específicas en lugares como América Latina. Con ello, los intentos por mejorar la calidad de vida de las comunidades se ven reforzados mediante la activación de los recursos locales, siendo que esta activación valorizaría el origen territorial de los bienes (Boucher, 2006). Bajo la concepción de SIAL todos los territorios cuentan con recursos genéricos y recursos específicos (socioculturales, económicos, o ambientales), que serían movilizados para promover iniciativas de desarrollo territorial (IICA, 2013a; 2013b, Requier-Desjardins, 2010). De tal forma, la activación de recursos locales se puede entender como la capacidad para movilizar, de manera colectiva, recursos específicos buscando mejorar la competitividad (Boucher, 2006, Requier-Desjardins, 2010).

Estos tres enfoques encuentran correspondencia empírica sustancial en países de América Latina, al menos desde la década de los años noventa. Entre las producciones más recientes que abordan los SIAL se pueden mencionar, por ejemplo, a Ayala (2018), Mancini (2012) o el ampliamente citado trabajo de Boucher (2004). Sobre APL y SPL se pueden mencionar los trabajos en América Latina de Madruga-Torres (2014), IICA (2013a; 2013b) o Patias, Marchi, Alves y Wittmann (2017).

10 Esta sería una característica fundamental distintiva de los SIAL, ya que enfoques como los distritos industriales o las agro industrias rurales dan especial relevancia a la concentración geográfica en espacios determinados y usualmente pequeños.

\section{Distinciones entre diferentes teorías}

Ante la variedad de enfoques para abordar aglomeraciones productivas, es sencillo perder el foco y presentar dificultades a la hora de escoger un lente teórico para interpretar la realidad. Tal hecho se ve exacerbado debido a que los enfoques estudiados tienen marcados aspectos en común, como las externalidades positivas de las concentraciones espaciales. Como si esto fuera poco, Martin y Sunley (2003) muestran lo confusos e incluso problemáticos que pueden resultar algunos de estos marcos teóricos. Con ello, se hace necesario tener algunos criterios que sirvan para diferenciar los enfoques presentados hasta ahora, lo que posibilitaría discernir el mejor marco teórico a utilizar dependiendo del objeto de investigación a ser abordado. Por ende, el siguiente acápite evidencia de forma clara qué diferencias se pueden encontrar en los enfoques descritos hasta ahora. Con tal fin, se han tomado en consideración cinco aspectos para caracterizar los marcos teóricos estudiados hasta ahora: el rigor teórico/metodológico, el tamaño de las empresas/unidades de análisis, la utilización de este enfoque para intervenciones en campo, de qué forma se aborda el territorio, y si el enfoque aborda de forma explícita temas agrícolas o agroalimentarios. El resumen del análisis realizado se muestra en la Tabla 1.

En primer lugar, los distritos industriales tienen el mayor rigor teórico de todos los enfoques discutidos. Existen estudios serios que han abordado el tema de la unidad de análisis (Becattini, 1979, citado en Brusco, 1990), y existe una formalización que permite identificar tales aglomerados, así como una metodología para definir cuál es la extensión de los mismos, mediante los mercados locales de trabajo. Con ello, existe una caracterización cuantitativa y cualitativa de qué son los distritos industriales. Por su parte, los clústeres son mucho más confusos, incluso desde la misma utilización de la palabra anglosajona cluster, que implica agrupación. Autores como Martin y Sunley (2003) y Malmberg y Power (2005) han atestiguado lo difuso que es el concepto, así como las dificultades a la hora de delimitar sus fronteras. 
Tabla 1. Diferencias entre distintos enfoques teóricos sobre aglomeraciones productivas

\begin{tabular}{|c|c|c|c|c|c|}
\hline Aspecto a evaluar & Distrito Industrial & Clúster & $\begin{array}{c}\text { Sistema } \\
\text { Productivo Local }\end{array}$ & $\begin{array}{c}\text { Arreglo } \\
\text { Productivo Local }\end{array}$ & $\begin{array}{c}\text { Sistema } \\
\begin{array}{c}\text { Agroalimentario } \\
\text { Localizado }\end{array}\end{array}$ \\
\hline $\begin{array}{l}\text { Rigor teórico / } \\
\text { metodológico }\end{array}$ & $\begin{array}{l}\text { Bueno. Unidad de } \\
\text { análisis de } \\
\text { mercado local de } \\
\text { trabajo. } \\
\text { Delimitación } \\
\text { cuanti y } \\
\text { cualitativa. }\end{array}$ & Vago. Confuso. & $\begin{array}{l}\text { Apropiación de } \\
\text { herencia de } \\
\text { distritos } \\
\text { industriales. } \\
\text { No formalizado. }\end{array}$ & $\begin{array}{c}\text { Vago y poco } \\
\text { desarrollado. } \\
\text { Menos } \\
\text { cohesionado que } \\
\text { los SPL. } \\
\text { ¿Indicadores? }\end{array}$ & $\begin{array}{l}\text { Medio. Frontera } \\
\text { que delimita al } \\
\text { SIAL es difusa. } \\
\text { Emanado de SPL. }\end{array}$ \\
\hline $\begin{array}{l}\text { Utilizado para } \\
\text { intervención en } \\
\text { campo. }\end{array}$ & $\begin{array}{c}\text { Investigación } \\
\text { económica para } \\
\text { apoyo a } \\
\text { decisiones } \\
\text { políticas (Sforzi, } \\
\text { 2012). }\end{array}$ & $\begin{array}{l}\text { Sí. Diversos } \\
\text { gobiernos. }\end{array}$ & $\begin{array}{l}\text { Variable. Utilizada } \\
\text { por gobiernos. } \\
\text { Herramienta } \\
\text { académica } \\
\text { analítica. }\end{array}$ & $\begin{array}{l}\text { Sí. Utilizada por } \\
\text { unidades de } \\
\text { gobierno. } \\
\text { (CARDOSO, 2014). }\end{array}$ & $\begin{array}{c}\text { Surge como } \\
\text { herramienta para } \\
\text { la intervención. } \\
\text { IICA, CIRAD. }\end{array}$ \\
\hline $\begin{array}{c}\text { ¿Cómo aborda el } \\
\text { territorio? }\end{array}$ & $\begin{array}{l}\text { Aborda valores, } \\
\text { normas, acuerdos } \\
\text { y comunidad. }\end{array}$ & $\begin{array}{l}\text { Telón de fondo. } \\
\text { Economía } \\
\text { neoclásica. } \\
\text { Enfocado en la } \\
\text { competitividad. }\end{array}$ & $\begin{array}{l}\text { Efecto de } \\
\text { proximidad de } \\
\text { territorio. }\end{array}$ & $\begin{array}{l}\text { Efecto de } \\
\text { proximidad de } \\
\text { territorio. }\end{array}$ & $\begin{array}{c}\text { Aborda el } \\
\text { territorio de } \\
\text { forma explícita. } \\
\text { Precede al análisis } \\
\text { del SIAL. }\end{array}$ \\
\hline $\begin{array}{l}\text { ¿Aborda de forma } \\
\text { explícita temas } \\
\text { agrícolas / agro } \\
\text { industriales? }\end{array}$ & $\begin{array}{c}\text { De forma } \\
\text { marginal. } \\
\text { Horticultura en } \\
\text { Italia o Vino. } \\
\text { Enfocado en } \\
\text { manufactura } \\
\text {. }\end{array}$ & $\begin{array}{l}\text { No es el foco, pero } \\
\text { sí aborda. (Vinos } \\
\text { California). }\end{array}$ & $\begin{array}{c}\text { Usualmente } \\
\text { enfocado en } \\
\text { manufacturas. } \\
\text { SPLs } \\
\text { especializados en } \\
\text { temas agro } \\
\text { alimentarios son } \\
\text { SIAL. }\end{array}$ & $\begin{array}{l}\text { Existen contados } \\
\text { estudios. }\end{array}$ & $\begin{array}{l}\text { Sí. Es su punto } \\
\text { central. }\end{array}$ \\
\hline $\begin{array}{l}\text { Tamaño de las } \\
\text { empresas/unidad } \\
\text { es de análisis }\end{array}$ & $\begin{array}{l}\text { Originalmente } \\
\text { empresas de porte } \\
\text { pequeño. } \\
\text { Tendencia a } \\
\text { crecer. }\end{array}$ & $\begin{array}{c}\text { Variado. } \\
\text { Tendencia a } \\
\text { empresas de gran } \\
\text { porte. }\end{array}$ & ¿Pequeño? & ¿Pequeño? & $\begin{array}{l}\text { Usualmente } \\
\text { pequeñas. }\end{array}$ \\
\hline
\end{tabular}

Fuente: elaboración propia.

Los sistemas productivos locales responden a la supuesta pérdida de rigor de los distritos industriales (Courlet, 2001). En sentido similar, Requier-Desjardins (1999) manifiesta que la evolución de los distritos industriales mostró una diversificación y heterogeneidad crecientes en las unidades involucradas, abriendo paso a grandes empresas, algunas de ellas inclusive ajenas a los propios distritos industriales. Pese a que usualmente los académicos franceses se apropian de este enfoque, no fue posible identificar aportes adicionales de los sistemas productivos locales que no hayan sido originalmente desarrollados por los distritos industriales. Ambos enfoques dan especial importancia a la comunidad, abordan explícitamente valores comunes e incluso remarcan el papel de la innovación y la cualificación. Pese a ello, los SPL muestran cierta debilidad teórica, por ejemplo, al no abordar una metodología clara a la hora de identificar sus límites geográficos.

Sobre los SPL, Madruga-Torres (2014) argumenta que "a pesar del amplio número de investigaciones que lo utilizan como referencia conceptual, resulta difícil encontrar una con el suficiente grado de precisión para evaluar su contenido y alcance analítico" (Madruga-Torres, 2014, p. 5). Peor suerte aún corren los APL, ya que tales aglomerados serían concentraciones de empresas con una menor intensidad en sus 
vínculos empresariales y comunitarios. Lo cual viene exacerbado por el hecho de que un APL podría ser fácilmente catalogado como un clúster de supervivencia, según la terminología de Altenburg y Meyer-Stamer (1999).

Por su parte, los SIAL suelen ser retratados como SPLs del sector agroalimentario. Con ello, se puede asumir que los vicios observados en los SPL puedan estar presentes en los SIAL. De forma similar a lo que sucede con SPL, APL o clúster; la identificación de los SIAL, así como la definición de sus fronteras, está sujeta a interpretación subjetiva. Requier-Desjardins (2010) resalta justamente que la dispersión de los territorios rurales hace que los límites espaciales del SIAL sean relativizados. Por otra parte, se verificó la existencia de diversas metodologías y acepciones de los factores que compondrían los SIAL. Sin ser exhaustivos, se identifican fácilmente abordajes diferentes para los SIAL según Muchnik (2006, 2012), Malafaia y Barcellos (2007) o Grass-Ramírez, Cervantes-Escoto y Palacios-Rangel (2012); lo que retrataría la permeabilidad de los SIAL. Con ello, se corre el riesgo de no poseer claridad sobre este enfoque y que la identificación, o delimitación del mismo, corra por cuenta personal del investigador. De la misma forma, al no tener fronteras teóricas claras, se corre el riesgo de que el SIAL sea utilizado para el estudio de objetos de investigación para los cuales este marco no provea el andamiaje teórico/metodológico necesario. De tal forma, la observación de Madruga-Torres (2014) parece pertinente, ya que la autora argumenta que existen varios vacíos empíricos y metodológicos para determinar cuando existen instancias productivo - territoriales como los SPL, clústeres y los distritos industriales.

Todos estos enfoques son utilizados en mayor o menor medida para la intervención en campo. La formalización teórica de los distritos industriales, por ejemplo, vino de la mano del Instituto Nacional de Estadística italiano y la academia de ese país europeo (ISTAT, 2001; Sforzi, 2012). Igualmente, los mercados locales de trabajo han pasado a ser una herramienta estadística oficial en Italia. No obstante, al menos a priori, no se identifica que los distritos industriales se formularan y desarrollaran con el objetivo explícito de intervención, y sí como un recurso de investigación económica y apoyo a decisiones políticas (Sforzi, 2012).

Por otra parte, los clústeres han sido utilizados por distintos gobiernos para fomentar la competitividad, llegando al punto de que uno de los más destacados autores que trabajan con esta perspectiva, Michael Porter, sea asesor en diversos gobiernos y agencias internacionales (Martin y Sunley, 2003). Los SPL y los APL han sido utilizados tanto como herramientas analíticas así como formas de intervención por parte de gobiernos. Por ejemplo, esto queda bastante bien retratado en el caso brasileño, con los estudios de Cassiolato y Szapiro (2002), Cassiolato, Lastres y Szapiro (2000) o Cardoso (2014).

Por su parte, los SIAL tienen su origen dentro de una organización internacional, específicamente el Centro de Cooperación Internacional sobre Investigación Agrícola para el Desarrollo (CIRAD). Con ello, aparentemente la visión de los SIAL, desde sus orígenes, era la intervención y la mejora de la calidad de vida de comunidades rurales, particularmente de Latinoamérica. Esto justifica parcialmente la tendencia en los estudios sobre SIAL hacia la activación de recursos $\mathrm{y}$, de esta forma, que existan incluso guías institucionales para dicha activación (IICA, 2011; 2013b).

Se ha confirmado que todos estos enfoques abordan las aglomeraciones productivas en espacios específicos. No obstante, tales enfoques se apropian del territorio en mayor o menor medida. Los distritos industriales definieron de forma clara a esta aglomeración productiva como una entidad socio territorial, resaltando la importancia de la comunidad donde el mismo distrito se ubica (Becattini, 1990). Algunos autores argumentan que cambiar el foco de análisis del sector industrial al distrito industrial es uno de los grandes aportes de Becattini (Sforzi, 2012; 2015). Con ello, los DI resaltaban características muchas veces obviadas en otros enfoques ortodoxos de economía, como los valores, los recursos humanos, la cooperación y la competencia. Por su parte, los clústeres originalmente no estaban preocupados con estas 
características territoriales, siendo el territorio únicamente el sustrato material donde se agrupaban empresas y donde podría existir una ventaja competitiva en relación a otras industrias o países. Por otra parte, tanto los SPL como los APL abordan el territorio de manera explícita. Por ejemplo, Courlet (2001) ya consideraba que los SPL se caracterizaban por la presencia de un territorio específico, donde existía un gran número de empresas cercanas e interrelacionadas.

De forma similar, para los SIAL el territorio también tendrá un papel importante, definiendo al mismo como el espacio construido histórica y socialmente, donde las actividades económicas están condicionadas por las relaciones de proximidad (Muchnik y Sautier, 1998). El territorio vendrá a justificar, por ejemplo dentro del SIAL, el por qué un bien específico puede poseer rasgos identitarios en un lugar y no tenerlos en otro. En ese sentido, Grass y Aguilar (2012) destacan:

\begin{abstract}
Se recomienda usar este enfoque cuando se quiere exaltar el valor de un producto alimenticio elaborado en un territorio, y que ha sido reconocido por ser un patrimonio cultural al transmitirse sus técnicas de elaboración de generación en generación o porque cuenta con características organolépticas que recogen las particularidades de la zona donde se produce, como el sabor o aroma de las materias primas que lo construyeron (Grass y Aguilar, 2012, pp. 55-56).
\end{abstract}

Si bien casi la totalidad de los enfoques ponen de manifiesto la importancia del territorio explícitamente, se ha podido constatar que todos ellos lo abordan alejados de la tradición del territorio dentro de la geografía, disciplina para la cual éste se erige como un concepto fundamental (Raffestin, 1993; Specht, 2009). En tal sentido, si bien la localización de las industrias ya había sido estudiada por autores clásicos como Marshall, la apropiación realizada por todos los marcos estudiados es mucho menos rigurosa que el utilizado en la geografía. Así, no fue identificada una discusión teórico epistemológica que permitiera comprender la apropiación del territorio por parte de los enfoques estudiados, particularmente desde perspectivas como la geografía política, que perciben al territorio como espacio de disputas y poder, como espacio de apropiación de recursos o como jurisdicción de un ente. En ese sentido, las discusiones sobre territorio y poder, abordadas por diversos autores como Raffestin (1993), Haesbaert (2011) o Schneider y Tartaruga (2004), están ausentes en los debates sobre todas las aglomeraciones productivas discutidas. Por lo tanto parece que se ignoran, de forma consciente o por omisión, las tensiones asociadas a vertientes territoriales más ortodoxas y se pasa a ver el territorio de una forma beneficiosa, sujeto de externalidades positivas y necesario para un desarrollo endógeno ${ }^{11}$. En el mismo sentido, (Salcido, 2013) expresa que: "De particular importancia para México y América Latina ha sido la identificación de los territorios con una idea romántica del origen, lo singular, lo específico y la identidad" (p. 72). Con ello, si bien se ha reafirmado de forma explícita la importancia del territorio en las aglomeraciones productivas expuestas hasta ahora, la misma posee poca relación con el territorio de la ciencia geográfica, particularmente de las escuelas clásicas y, en palabras de Schneider y Tartaruga (2004), este territorio pasaría a ser sinónimo de espacio o región, destacando particularmente las características positivas del mismo, dejando así de lado el gran bagaje teórico del concepto desde la geografía. Este tratamiento parcializado ha hecho posible el abordaje del territorio centrándose en las bondades que el mismo ofrece, usualmente marginalizando efectos negativos potenciales en las aglomeraciones productivas. Sobre el particular, Requier-Desjardins (2010; 2017) ha identificado recientemente algunos efectos negativos asociados a actividades rurales en Colombia, como la deforestación y la competencia entre territorios en la producción de panela (Requier-Desjardins, 2010; 2017). Aún sobre relaciones conflictivas, Hinrichs (2000) destaca que los SIAL no son capaces de

11 Dentro de la discusión teórica sobre territorio, este impase sería superado mediante la visión híbrida y multiescalar del territorio propuesta por Haesbaert (2011) o la visión instrumental del territorio propuesta por Schneider y Tartaruga (2004). 
aislarse de las relaciones de poder que ejercen los consumidores de clase media al procurar productos territoriales; lo que abriría espacio a posibles conflictos. Asimismo, Mancini (2012) ha retratado la exclusión de productores a la hora de elaborar la indicación geográfica del queso Chontaleño en Nicaragua.

Por otra parte, resulta importante dilucidar qué enfoques abordan de forma directa los sectores agropecuarios y agroindustriales. En tal sentido, los distritos industriales tuvieron originalmente una vocación por la industria manufacturera. Estudios como el de Sforzi (2012) retratan que la mayoría de los distritos industriales en Italia tenían origen en la zapatería (11), la mueblería (12) y en la producción de prendas de vestir (15). Sólo estudios más recientes han pasado a abordar distritos hortícolas (Belussi y Sedita, 2010; Belussi, 2015). Pese a ello, estudios como el de Christerson y Lever-Tracy (1997) retratan la existencia de distritos industriales en espacios rurales, si bien los mismos se desarrollan usualmente en sectores ajenos a los agropecuarios/agroindustriales.

Algo parecido sucede con los clústeres, ya que estos abordan los temas agropecuarios/ agro industriales de forma marginal. Pese a ello, estudios como los de Porter (1998b), retratan la existencia de clústeres de vinos en California y Portugal, o de comida enlatada y cereales (Porter, 1998a). En los SPL y APL, el sesgo parece ser similar, al existir menor cantidad de estudios que se dediquen al sector agroalimentario (Teixeira et al., 2006; Patias et al., 2017). De tal forma, resaltan trabajos sobre SPL y APL en sectores similares a los vistos en los DI o clústeres, como los realizados en el sector de los muebles (Fernández y Ariza, 2004), o en el del calzado y el automotriz en Brasil (Santos, Crocco y Lemos, 2002). Esta parece ser una de las mayores fortalezas del SIAL, ya que el mismo estudia desde su origen temas agroalimentarios. En este sentido, los SIAL son considerados como SPL exclusivos del sector agroalimentario (Requier-Desjardins, 2010), si bien autores como Boucher (2006) destacan la particularidad de los SIAL y argumentan que su relevancia teórica excedería a los propios
SPL. De tal suerte, los SIAL han sido utilizados para estudiar, particularmente en América Latina, transformaciones agroalimentarias de bienes con un fuerte anclaje territorial. Así, se identifican trabajos estudiando alimentos como las fresas en Brasil (Specht, 2009), el maíz en El Salvador (Ayala, 2018), o los quesos en Nicaragua (Mancini, 2012) y Perú (Boucher, 2004).

Finalmente, vale la pena destacar que, originalmente, el tamaño de las empresas asociadas a los distritos industriales era de pequeñas o medianas, pese a que el porte de las mismas ha sido posteriormente relativizado, llegando a abarcar grandes firmas (Brusco, 1990; Sforzi y Mancini, 2012; Bellandi y De Propris, 2015). Por su parte, los clústeres suelen presentar una tendencia a beneficiar empresas de tamaño grande. Desde su concepción inicial de la ventaja comparativa de los países, Porter (1990) daba especial realce a las compañías que se desempeñaban mejor en su respectivo sector del mercado internacional. No obstante, la clasificación de clústeres de Altenburg y Meyer-Stamer (1999) relativiza tal tendencia, al dar cuenta de la existencia de clústeres de supervivencia, por ejemplo. Para los SPL y los APL el terreno resulta más difuso. Todo indica que existe una idea de asociación de pequeñas o medianas empresas (Rendón y Forero, 2014). No obstante, las definiciones elaboradas por Cardoso (2014) sobre APL o Madruga-Torres (2014) sobre SPL, no hacen referencia explícita al tamaño de las empresas. De la misma forma, en las discusiones sobre APL y SPL, no se identifica una discusión teórica o metodológica sobre las unidades de análisis apropiadas. Por su parte, los SIAL están asociados a pequeñas empresas $y$ usualmente vinculados a lugares remotos, particularmente de América Latina, como el Vale do Taquari (Specht, 2009) o Cajamarca (Boucher, 2004). Vale la pena destacar, al respecto, que los SIAL nacen en el seno de una organización internacional, con una clara intención de realizar intervenciones para el desarrollo. Con ello, desde el inicio se puede identificar un sesgo hacia los pequeños productores o pequeñas agro industrias rurales. 


\section{Consideraciones Finales}

Lejos de agotar los enfoques teóricos utilizados para estudiar aglomeraciones productivas en espacios específicos, el presente artículo se ha centrado en cinco marcos teóricos relevantes y ampliamente utilizados en investigaciones. Como se ha podido evidenciar, los cinco enfoques estudiados guardan importantes similitudes. Una de las más notorias es que todos ellos entienden el espacio como una característica importante y beneficiosa del desarrollo o crecimiento económico, dando por válida la posibilidad de alcanzar un desarrollo endógeno. Los DI lo materializan mediante el crecimiento económico, en sentido similar los clústeres se centran en el aumento de la competitividad y sus indicadores económicos relacionados, mientras que los SIAL entienden el desarrollo de regiones específicas en función de la activación de recursos territoriales.

De tal suerte, las similitudes existentes pueden hacer mucho más difícil la tarea de diferenciar los enfoques y escoger el más adecuado para el caso particular. Tomando en consideración las palabras de Belussi (2015), vivimos en el mundo académico donde existe ambigüedad semántica y lo que en un lugar se conoce como clúster puede representar en realidad una teorización de los distritos marshallianos al estilo de los economistas italianos de los años ochenta. De tal forma, esa ambigüedad podría sugerir que escoger y utilizar algunos de los cinco marcos teóricos discutidos en el presente trabajo podría realizarse de forma aleatoria y sin mayores consecuencias teóricas, metodológicas o prácticas. Pese a ello, y tomando en consideración que un marco teórico es la herramienta que nos permite interpretar y analizar la realidad, las diferencias expuestas sobre los enfoques mencionados inducen también al tratamiento y abordaje de los problemas de investigación de forma diferenciada. De esa forma, por ejemplo, la utilización de los clústeres como enfoque teórico nos instiga a realizar análisis de carácter macro y desde una perspectiva nacional/regional/ internacional, volcándose por temas relacionados a la competitividad, como condiciones de oferta y demanda o las diversas estrategias empresariales. Similarmente, y en función de su origen histórico, este marco teórico posibilitará realizar un abordaje territorial mucho más laxo y menos enfocado en el lugar donde acontece la aglomeración productiva.

Por otra parte, los Distritos Industriales podrían también tratar temas sobre competitividad o estrategias empresariales; no obstante, para los DI la comunidad y el territorio donde suceden las aglomeraciones productivas sí serían trascendentales. Adicionalmente, el uso de los distritos industriales podría permitir la adopción de una escala menor a la evidenciada en los clústeres, ya que los DI se basan en los mercados locales de trabajo, dando importancia a las particularidades territoriales de la aglomeración y prestando atención a temas como los valores o la cohesión de los actores.

Adicionalmente, un elemento aparentemente común a estos dos enfoques sería la importancia de contar con indicadores y estadísticas preexistentes para los análisis regionales, ya que los clústeres necesitan de estadísticas económicas para abordar temas de competitividad, mientras que los distritos industriales utilizan estadísticas económicas para definir espacialmente el alcance de los mercados locales de trabajo. Con ello, si no existiese este tipo de información estadística, otros enfoques resultarían probablemente más apropiados. De esa forma, dado que clústeres y distritos industriales descansan sobre estadísticas confiables y permiten la elaboración de análisis sectoriales, los mismos son utilizados por parte de poderes públicos de varios países, especialmente en lo que se refiere al análisis y planeación de políticas públicas volcados para medianas y grandes empresas. En tal sentido, los distritos industriales siguen utilizándose en la actualidad dentro del sistema nacional de estadísticas en Italia (ISTAT, 2015), mientras que los clústeres han sido usados por gobiernos de países como Francia, Alemania o Reino Unido (Martin y Sunley, 2003).

Por otra parte, los enfoques surgidos a finales de los años noventa (SPL, APL y SIAL) muestran similitudes con el DI a la hora de abordar explícitamente la cuestión territorial; dando 
importancia a los actores implicados en la aglomeración, así como a sus interrelaciones. Pese a ello, y a diferencia de lo que ocurre con los DI, la frontera física que delimita la aglomeración productiva en los tres marcos parece ser mucho más porosa y, en el caso específico de los SIAL, es posible identificar incluso territorios discontínuos (Requier-Desjardins, 2010). En tal sentido, los tres enfoques concederían una flexibilidad adicional al investigador, particularmente si se compara con el caso de los DI.

Otra particularidad de los SPL, APL y SIAL sería que no descansan obligatoriamente sobre la base de estadísticas económicas oficiales, a diferencia de los distritos industriales o los clústeres. De tal suerte, los SPL, APL y SIAL se apoyan grandemente sobre información cualitativa. En función de sus especificidades $y$, a nivel de política pública, los tres enfoques podrían ser empleados por autoridades públicas encargadas de pequeñas y medianas empresas, tanto en espacios rurales como urbanos; como lo ejemplifica Cardoso (2014).
Finalmente, la revisión realizada de la literatura muestra indicios apuntando a que los sistemas productivos locales, arreglos productivos locales y sistemas agroalimentarios localizados, han sido ampliamente utilizados para centrarse en países de América Latina. Ya los distritos industriales y los clústeres son más evidentes en trabajos realizados en países de Europa y Estados Unidos. Al centrarse en temas de investigación sobre el mundo rural y en las transformaciones agro industriales, se ha identificado que los enfoques más utilizados han sido (en orden decreciente) SIAL, SPL, APL; pese a que los dos últimos no eran empleados originalmente para el estudio del mundo rural.

$\mathrm{Al}$ señalar estas diferencias, y particularmente evidenciar las fronteras entre los marcos interpretativos estudiados, se espera clarificar y ayudar a escoger la mejor teoría en función del objeto de estudio particular. De tal forma, se confía en impactar la producción de nuevos estudios, ya que al existir mayor claridad teórica, se vuelve más fácil el trabajo de ampliación y difusión del conocimiento sobre tales temáticas.

\section{Referencias bibliográficas}

Altenburg, T. y Meyer-Stamer, J. (1999). How to Promote Clusters: Policy Experiences from Latin America. World Development, 27(9), 1693-1713. https://doi.org/10.1016/S0305-750X(99)00081-9

Ambrosini, L., Filippi, E. y Miguel, L. (2008). SIAL: Analise da produção agroalimentar a partir de um aporte territorialista e multidisciplinar. Ideas: Interfaces em desenvolvimento, agricultura e sociedade, 2(1), 6-31.

Ayala, C. (2018). Sistema Agroalimentario localizado del maíz blanco en Ciudad Arce, municipio de El Salvador (tesis doctoral). Universidade Federal do Rio Grande do Sul, Porto Alegre, Brasil. http:// hdl.handle.net/10183/183066

Becattini, G. (1990). The Marshallian industrial district as a socioeconomic notion. En F. Pyke, G. Becattini y W. Sengenberger (Eds.), Industrial districts and inter-firm co-operation in Italy (pp. 3751). Ginebra, Suiza: International Labour Organisation.

Bellandi, M. y De Propris, L. (2015). Three Generations of Industrial districts. Investigaciones Regionales - Journal of Regional Research, (32), 75-87.

Belussi, F. (2015). The international resilience of Italian industrial districts/clusters (ID/C) between knowledge re-shoring and manufacturing off (near)-shoring. Investigaciones Regionales - Journal of Regional Research, (32), 89-113.

Belussi, F. y Sedita, S. (2010). Local systems playing globally: heterogeneous districts in the ornamental horticulture global value chain. En F. Belussi y A. Samara (Eds.), Business Networks in Clusters and Industrial Districts (pp. 215-245). Nueva York, Estados Unidos: Routledge. 
Boix, R. y Galletto, V. (2008). Marshallian Industrial Districts in Spain. Scienze Regionali, 7(3), 29-52.

Boix, R. y Trullén, J. (2011). La relevancia empírica de los distritos industriales marshallianos y los sistemas productivos locales manufactureros de gran empresa en España. Investigaciones Regionales, (19), 75-96. http://hdl.handle.net/10017/29268

Boucher, F. (2004). Enjeux et difficultés d'une stratégie collective d'activation des concentrations d'agro-industries rurales : le cas des fromageries rurales de Cajamarca au Pérou (tesis doctoral). Universidad de Versailles, Versalles, Francia. Recuperado de http://www.theses.fr/2004VERSo30S

Boucher, F. (2006). Agroindustria Rural y Sistemas Agroalimentarios Locales. Nuevos enfoques de desarrollo territorial. Presentado en III Congreso Internacional de la red SIAL: Alimentacion y Territorios, Baeza, España.

Boucher, F. y Pomeón, T. (2010). Reflexiones en torno al enfoque SIAL: Evolución y avances desde la Agroindustria Rural (AIR) hasta los sistemas Agroalimentarios Localizados (SIAL). Presentado en $116^{\text {th }}$ EAAE seminar "Spatial Dynamics in Agri-food Systems: Implications for Sustainability and Consumer Welfare", Parma, Italia.

Boucher, F. y Riveros, H. (1995). La agroindústria rural de América Latina y El Caribe. Tomo I: Su entorno, Marco Conceptual e Impacto. Serie de Estudios de Agroindustria Rural. San José, Costa Rica: PRORAD.

Brusco, S. (1990). The idea of the Industrial District: Its genesis. En F. Pyke, G. Becattini y W. Sengenberger (Eds.), Industrial districts and inter-firm co-operation in Italy (pp. 10-19). Ginebra, Suiza: International Labour Organisation.

Cambridge Dictionary. (2018). Cluster. Recuperado de https:/dictionary.cambridge.org/es/ diccionario/ingles-espanol/cluster

Capecchi, V. (1990). A history of flexible specialisation and industrial districts in Emilia-Romagna. En F. Pyke, G. Becattini y W. Sengenberger (Eds.), Industrial districts and inter-firm co-operation in Italy (pp. 20-36). Ginebra, Suiza: International Labour Organisation.

Cardoso, E. (2014). APL: Arranjo produtivo local. Série Empreendimentos Coletivos. Brasília, Brasil: SEBRAE.

Cassiolato, J. E. y Szapiro, M. (2002). Arranjos e Sistemas Produtivos e Inovativos Locais no Brasil. Proposição de Políticas para a Promoção de Sistemas Produtivos Locais de Micro, Pequenas e Médias empresas. Rio de Janeiro, Brasil: IE/UFRH.

Cassiolato, J., Lastres, H. y Szapiro, M. (2000). Arranjos e Sistemas Produtivos Locais e Proposições de Políticas de Desenvolvimento Industrial e Tecnológico. Nota técnica 27. Rio de Janeiro, Brasil: Instituto de Economia da Universidade Federal do Rio de Janeiro. Recuperado de http://www. ie.ufrj.br/redesist/P2/textos/NT27.PDF

Christerson, B. y Lever-Tracy, C. (1997). The third China? Emerging Industrial Districts in Rural China. International Journal of Urban and Regional Research, 21(4), 569-588. https://doi. org/10.1111/1468-2427.00102

CIRAD-SAR -Centre De Coopération Internationale En Recherche Agronomique Pour Le Développement-. (1996). Systèmes Agroalimentaires Localisés: organisations, innovations et developpement local orientations et perspectives issues de la consultation du CIRAD. Stratégies de 
recherche dans le domaine de la socio-économie de l'alimentation et des industries agroalimentaires. Paris, Francia: CIRAD-SAR.

Costanza, R., Cumberland, J., Daly, H., Goodland, R. y Norgaard, R. (1997). An introduction to ecological economics. Boca Ratón, Estados Unidos: St. Lucie Press.

Courlet, C. (2001). Les systèmes productifs localisés : un bilan de la littérature. Cahiers d'économie et de sociologie rurales, (58-59), 82-103.

Courlet, C. (2013). Os sistemas produtivos localizados: da definição ao modelo. Interthesis, 10(2), 3369. https://doi.org/10.5007/1807-1384.2013v10n2p33

Fernández, L. y Ariza, J. (2004). Análisis estratégico de los sistemas productivos locales: el caso del mueble de Lucena (Córdoba, España). Revista de Estudios Regionales, (71), 109-129.

Gliessman, S. (2002). Agroecología: Procesos ecológicos en agricultura sostenible. Turrialba, Costa Rica: CATIE.

Gliessman, S. y Rosemeyer, M. (2010). The conversion to sustainable agriculture. Florida, Estados Unidos: CRC Press.

Gottman, J. (1975). The evolution of the concept of territory. Social Science Information, 14(3), 29-47. https://doi.org/10.1177/053901847501400302

Grass, J. y Aguilar, J. (2012). El enfoque de Sistemas Agroalimentarios Localizados (SIAL). Textual, (60), 45-60.

Grass-Ramírez, I., Cervantes-Escoto, F. y Palacios-Rangel, M. (2012). El enfoque de sistemas agroalimentarios localizados - SIAL: propuestas para El fortalecimiento metodológico. Reporte de Investigación 92. Chapingo, México: Universidad Autónoma de Chapingo.

Haesbaert, R. (2011). El mito de la desterritorialización: del Fin de los territorios a la multiterritorialidad. Ciudad de México, México: Siglo XXI.

Herrera, Y. (2014). Arreglos productivos locales en Cuba. Propuesta para su desarrollo. Economía y Desarrollo, 152(2), 155-167.

Hervas, J. L. y Boix, D. (2013). The Economic Geography of the Meso-global Spaces: Integrating Multinationals and Clusters at the Local-Global Level. European Planning Studies, 21(7), 10641080. https://doi.org/10.1080/09654313.2013.733853

Hinrichs, C. C. (2000). Embeddedness and local food systems: notes on two types of direct agricultural market. Journal of Rural Studies, 16(3), 295-303. https://doi.org/10.1016/S0743-0167(99)00063-7

Huggins, R. e Izushi, H. (2011). Competition, competitive advantage, and clusters: the ideas of Michael Porter. En R. Hugginsy H. Izushi (Eds.), Competition, competitive advantage, and clusters: the ideas of Michael Porter (pp. 1-24). Oxford, Reino Unido: Oxford University Press.

IICA -Instituto Interamericano para la Cooperación Agrícola-. (2011). Guía Metodológica para la activación de sistemas agroalimentarios localizados (SIAL). Ciudad de México, México: IICA, CIRAD, RED-SIAL.

IICA -Instituto Interamericano para la Cooperación Agrícola-. (2013a). Desarrollo Territorial con Enfoque de Sistemas Agroalimentarios Localizados (AT-SIAL). Sur Alto, Costa Rica: IICA. 
IICA -Instituto Interamericano para la Cooperación Agrícola- (2013b). Guía metodológica para la Activación Territorial con enfoque de Sistemas Agroalimentarios Localizados (AT-SIAL). Ciudad de México, México: IICA.

Isard, W. (1956). Location and Space-Economy. Londres/Nueva York, Reino Unido/Estados Unidos: Technology Press of Massachusetts Institute of Technology, John Wiley \& Sons Inc., Chapman \& Hall Ltd.

ISTAT -Istituto Nazionale Di Statistica-. (2001). 8 Censimento generale dell'industria e dei servizi. Roma, Italia: ISTAT.

ISTAT -Istituto Nazionale Di Statistica-. (2015). La nuova geografia dei sistemi locali. Roma, Italia: ISTAT.

Lastres, H. y Cassiolato, J. (2005). Mobilizando Conhecimentos para Desenvolver Arranjos e Sistemas Produtivos e Inovativos Locais de Micro e Pequenas Empresas no Brasil. Rio de Janeiro, Brasil: REDESIST/SEBRAE. Recuperado de https://tinyurl.com/y7qmz4hd

Lösch, A. (1954). Economics of Location. New Heaven, Estados Unidos: Yale University Press.

Madruga-Torres, A. (2014). Los sistemas productivos locales en la gestión del desarrollo local en Cuba. Ciencias Holguín, 20(3), 1-12.

Malafaia, G. C. y Barcellos, J. (2007). Sistemas Agroalimentares Locais e a Visão Baseada em Recursos: construindo vantagens competitivas para a carne bovina gaúcha. Revista de Economia e Agronegócio, 5(1), 25-50. https://doi.org/10.22004/ag.econ.55171

Malmberg, A. y Power, D. (2005). (How) Do (Firms in) Clusters Create Knowledge? Industry and Innovation, 12(4), 409-431. https://doi.org/10.1080/13662710500381583

Mancini, M. C. (2012). Localised Agro-Food Systems and Geographical Indications in the Face of Globalisation: The Case of Queso Chontaleño. Sociologia Ruralis, 53(2), 180-200. https://doi. org/10.1111/soru.12004

Marshall, A. (1895). Principles of Economics, 2 ed. Londres, Reino Unido: Cambridge University Press.

Martin, R. y Sunley, P. (2003). Deconstructing Clusters: Chaotic Concept or Policy panacea? Journal of Economic Geography, 3(1), 5-35. https://doi.org/10.1093/jeg/3.1.5

Muchnik, J. (2006). Sistemas Agroalimentarios Localizados: evolución del concepto y diversidad de situaciones. Presentado en III Congreso Internacional de la red SIAL: Alimentacion y Territorios, Baeza, España.

Muchnik, J. (2012). Sistemas agroalimentarios localizados: desarrollo conceptual y diversidad de situaciones. En G. Salcido y R. Torres (Eds.), Los sistemas agroalimentarios localizados. Identidad territorial, construcción de capital social e instituciones (p. 42-52). Ciudad de México, México: UNAM.

Muchnik, J. y Sautier, D. (1998). Systèmes agro-alimentaires localisés et construction de territoires. Proposition d'action thématique programmée. Paris, Francia: CIRAD.

Patias, T., Marchi, J., Alves, L. y Wittmann, M. (2017). Governança de arranjo produtivo local: um estudo de caso no APL do Leite de Santana do Livramento, RS, Brasil. Gestão \& Produção, 24(3), 622-635. https://doi.org/10.1590/0104-530x1218-16 
Aglomeraciones productivas, territorio y abordajes teóricos para los estudios rurales

Porter, M. (1990). The competitive Advantage of Nations. Harvard Bussiness Review, 68(2), 70-91.

Porter, M. (1998a). Clusters and Competition. New Agendas for Companies. Massachussets, Estados Unidos: Harvard Business School.

Porter, M. (1998b). Clusters and the new economics of competition. Harvard Business Review, 76(6), 77-90.

Porter, M. (2000). Location, Competition, and Economic Development: Local clusters in a Global Economy. Economic Development Quarterly, 14(1), 15-34. https://doi.org/10.1177/089124240001400105

Pyke, F. y Sengenberger, W. (1990). Introduction. En F. Pyke, G. Becattini y W. Sengenberger (Eds.), Industrial districts and inter-firm co-operation in Italy (pp. 1-9). Ginebra, Suiza: International Labour Organisation.

Racine, J. B., Raffestin, C. y Ruffy, V. (1983). Escala e Ação: contribuições para uma interpretação de mecanismo de escala prática da geografia. Revista Brasileira de Geografia, 45(1), 123-35.

Raffestin, C. (1993). Por uma Geografia do Poder. São Paulo, Brasil: Ática.

Rendón, J. y Forero, J. (2014). Sistemas productivos locales: estrategias empresariales para el desarrollo. Semestre Económico, 17(35), 75-94. https://doi.org/10.22395/seec.v17n35a3

Requier-Desjardins, D. (1999). Agro-Industria Rural y Sistemas Agroalimentarios Localizados: ¿Cuáles puestas? Quito, Ecuador: PRODAR.

Requier-Desjardins, D. (2010). L'évolution du débat sur les SYAL : le regard d'un économiste. Revue d'Économie Régionale \& Urbaine, 4(1), 651-668. https://doi.org/10.3917/reru.104.0651

Requier-Desjardins, D. (2017). La demanda: impacto sobre las dinámicas de desarrollo territorial de los Sial en América Latina. Estudios Latinoamericanos, 40(1), 75-94. https://doi.org/10.22201/ cela.24484946e.2017.40.61592

Requier-Desjardins, D., Boucher, F. y Cerdan, C. (2003). Globalization, competitive advantages and the evolution of production systems: rural food processing and localized agri-food systems in Latin-American countries. Entrepreneurship \& Regional Development, 15(1), 49-67. https://doi.org/ $10.1080 / 08985620210144983$

Salcido, G. (2013). Sistemas agroalimentarios localizados. Innovación y debates desde América Latina. Interthesis, 10(2), 68-94. https://doi.org/10.5007/1807-1384.2013v10n2p68

Salcido, G. (2017). Apuntes sobre los Sistemas Agroalimentarios Localizados. Del Distrito Industrial al desarrollo territorial. Estudios Latinoamericanos, 4O(1), 19-36. https://doi.org/10.22201/ cela.24484946e.2017.40.61575

Santos, F., Crocco, M. y Lemos, M. (2002). Arranjos e sistemas produtivos locais em "espaços industriais" periféricos: estudo comparativo de dois casos brasileiros. Belo Horizonte, Brasil: UFMG/Cedeplar.

Schneider, S. y Tartaruga, I. G. (2004). Território e Abordagem Territorial: das referências cognitivas aos aportes aplicados à análise dos processos sociais rurais. Raízes, 23(1), 99-116.

Sforzi, F. (1990). The quantitative importance of Marshallian industrial districts in the Italian Economy. En F. Pyke, G. Becattini y W. Sengenberger (Eds.), Industrial districts and inter-firm cooperation in Italy (pp. 75-107). Ginebra, Suiza: International Labour Organisation. 
Sforzi, F. (2012). From Administrative Spatial Units to Local Labour Market Areas. Some Remarks on the Unit of Investigation of Regional Economics with Particular Reference to the Applied Research in Italy. En E. Vásquez y F. Morrollón (Eds.), Defining the Spatial Scale in Modern Regional Analysis. New Challenges from Data at Local Level (pp. 3-21). Londres, Reino Unido: Springer.

Sforzi, F. (2015). Rethinking the industrial district: 35 years later. Investigaciones Regionales - Journal of Regional Research, (32), 11-29.

Sforzi, F. y Mancini, M. (2012). The Reinterpretation of the Agri-Food System and Its Spatial Dynamics through the Industrial District. Agricultural Economics - Zemědělská ekonomika, 58(11), 510-519.

Specht, S. (2009). O território do morango no Vale do Caí - RS: análise pela perspectiva dossistemas agroalimentares localizados (tesis de doctorado). Universidade Federal do Rio Grande do Sul, Porto Alegre, Brasil.

Teixeira, K., Amaral-Filho, J., Mayorga, R. y Mayorga, M. I. (2006). Território, cooperação e inovação: um estudo sobre o Arranjo Produtivo Pingo D’água. Revista de Economia e Sociologia Rural, 44(3), 573-594. https://doi.org/10.1590/S0103-20032006000300010

Wives, D., Ayala, C., Senna H. y Kühn, I. (2017). Espaço e suas categorias de análise no olhar da Geografia. En J. D. D. Ramos y D. Wives (Org.), Natureza do espaço e o desenvolvimento (pp. 11-42). Porto Alegre, Brasil: Editora UFRGS. 